\title{
Limited systemic sclerosis
}

INSERM

\section{Source}

INSERM. (1999). Orphanet: an online rare disease and orphan drug data base. Limited systemic sclerosis. ORPHA:220407

Limited systemic sclerosis (ISSc) (or SSc sine scleroderma) is a subset of systemic sclerosis (SSc; see this term) characterized by organ involvement in the absence of fibrosis of the skin. 